\title{
Etnomatematika: Eksplorasi Transformasi Geometri Tenun Suku Sasak Sukarara
}

\author{
Sutarto $^{1}$, Intan Dwi Hastuti ${ }^{2}$, Sri Supiyati ${ }^{3}$ \\ ${ }^{1}$ Program Studi Pendidikan Matematika, Universitas Pendidikan Mandalika \\ ${ }^{2}$ Program Studi PGSD, Universitas Muhammadiyah Mataram \\ ${ }^{3}$ Program Studi Pendidikan Matematika, Universitas Hamzanwadi \\ *intandwihastuti88@gmail.com
}

\begin{abstract}
Abstrak
Matematika dianggap sebagai mata pelajaran yang masih jauh dari kenyataan dan budaya. Secara historis, matematika berkaitan erat dengan kehidupan sehari-hari, termasuk budaya di Lombok Nusa Tenggara Barat. Budaya ini dapat digunakan untuk menggali konsep-konsep matematika sebagai upaya untuk mendekatkan matematika dengan realitas dan persepsi masyarakat dan aspek budaya juga menjadi dasar pembelajaran matematika di sekolah. Oleh karena itu, penelitian ini bertujuan untuk mengeksplorasi unsur transformasi geometri tenun suku Sasak Sukarara Lombok Tengah menurut sudut pandang etnomatematika. Penelitian ini merupakan penelitian kualitatif dengan pendekatan etnografi. Metode pengumpulan data dilakukan melalui observasi dan wawancara dengan tokoh budaya dan penenun asli Sukarara Lombok Tengah. Teknik analisis data dalam penelitian ini menggunakan teknik analisis isi dan triangulasi. Teknik analisis isi menyajikan data secara detail tentang budaya menenun dan kebiasaan subjek penelitian yang dilakukan di lokasi penelitian. Teknik triangulasi sumber data dilakukan dengan menggali secara komprehensif hubungan antara sistem pengetahuan matematika dan budaya motif tenun serta melihat konsepsi matematis yang ada dalam motif tenun Sukarara. Hasil penelitian ini menunjukkan bahwa motif wayang, subahnale, keker, bintang empat, dan alang/lumbung ditemukan konsep refleksi (pencerminan) dan translasi (pergeseran) yang dapat dijadikan sumber belajar materi transformasi geometri.
\end{abstract}

Kata kunci: etnomatematika, transformasi geometri, tenun Sasak, Sukarara

\begin{abstract}
Mathematics is considered as a subject that still far from reality and culture. Historically, mathematics has closely related to everyday life, including culture in Lombok West Nusa Tenggara. This culture can explore mathematical concepts to bring mathematics closer to reality and people's perceptions and cultural aspects as the basis for learning mathematics in schools. Therefore, this study explores the elements of geometry transformation in the weaving of the Sasak Sukarara tribe of Central Lombok from an ethnomathematics point of view. This research is qualitative research embracing an ethnographic approach. Data collection methods were carried out through observation and interviews with cultural leaders and native weavers from Sukarara, Central Lombok. The data analysis technique in this study used content analysis and triangulation techniques. The content analysis technique provides detailed data dealing with the weaving culture and habits of the research subjects carried out at the research location. The data source triangulation technique was carried out by comprehensively exploring the relationship between the mathematical knowledge system and the weaving motif culture and looking at the mathematical conceptions that exist in the Sukarara weaving motif. This study showed that in the motifs of wayang, subahnale, keker, four stars, and alang/lumbung, the concepts of reflection and translation could be used as learning resources for geometry transformation materials.
\end{abstract}

Keywords: ethnomathematics, geometry transformation, Sasak weaving, Sukarara 


\section{Pendahuluan}

Tujuan utama pembelajaran matematika bukan hanya sekedar untuk transfer ilmu pengetahuan, tetapi dapat mendorong penciptaan pengetahuan baru. Pembelajaran matematika perlu dikaitkan dengan budaya atau kehidupan sehari-hari siswa karena pada dasarnya matematika tidak bisa berdiri sendiri dan sangat dipengaruhi oleh aspek sejarah, geografi, lingkungan sosial (D'ambrosio, 2016; Prahmana, Yunianto, Rosa, \& Orey, 2021). Pembelajaran matematika perlu melibatkan budaya dan kehidupan yang ada di sekitar siswa agar bermakna dan siswa lebih mudah memahami konsep matematika yang akan dipelajari dalam kehidupan sehari-hari (Risdiyanti \& Prahmana, 2017).

Disiplin penelitian yang mengeksplorasi hubungan antara matematika dan budaya adalah etnomatematika (Supiyati \& Halqi, 2019). Etnomatematika pertama kali diperkenalkan oleh D'Ambrosio, seseorang matematikawan asal Brazil dan etnomatematika mempelajari bagaimana ide matematika dan praktik matematika diproses dan digunakan sekelompok budaya dalam aktivitas sehari-hari (D’Ambrosio, 2016; Rosa \& Orey, 2016). Marsigit (2016) menyatakan bahwa etnomatematika merupakan suatu ilmu yang mengombinasikan matematika dan budaya serta mengeksplorasi hubungan diantara keduanya. Dalam etnomatematika, guru dapat mengkontekstualisasikan pengajaran dan pembelajaran matematika dengan menghubungkan konten matematika dengan pengalaman sosiokultural siswa. Etnomatematika sebagai inovasi dalam pembelajaran matematika yang bertujuan agar siswa mencintai matematika, termotivasi, dan meningkatkan kreativitas dalam mengerjakan matematika (Marsigit \& Mauluah, 2019). Oleh karena itu, keterlibatan etnomatematika dalam proses pembelajaran matematika akan membuat siswa lebih mudah memahami konsep matematika yang akan dipelajari, karena etnomatematika menjembatani matematika sekolah dengan dunia sehari-hari siswa yang berbasis pada budaya lokal. Etnomatematika juga dapat meningkatkan rasa cinta terhadap budaya dan sebagai upaya untuk mencegah lunturnya nilainilai kearifan lokal.

Etnomatematika relevan dengan implementasi kurikulum yang berorientasi pada penguatan karakter siswa. Dalam kurikulum 2013 yang berlaku di Indonesia menekankan pada aspek penguatan karakter, perkembangan ilmu pengetahuan, budaya, teknologi, dan seni yang dapat membangun keingintahuan siswa (Peraturan Menteri Pendidikan dan Kebudayaan No 21 Tahun 2016). Pembelajaran yang mengeksplorasi budaya lokal mampu membuat siswa untuk mencintai daerah dan bangsanya (Hastuti, Surahmat, Sutarto, 2019; Widodo, 2019). Muatan lokal merupakan bagian dari struktur kurikulum yang termuat dalam Standar Isi 
kurikulum pendidikan di Indonesia. Muatan lokal mencakup bahasa daerah, kesenian daerah, keterampilan dan kerajinan, adat istiadat, dan lingkungan alam sekitar.

Beberapa penelitian etnomatematika telah dikaji di Indonesia seperti, penentuan hari baik untuk membangun rumah pada masyarakat Cigugur (Umbara, Wahyudin, Prabawanto, 2021), pembelajaran geometri melalui pola batik Yogyakarta (Prahmana \& D’Ambrosio, 2020), konsep geometri transformasi kerajinan tenun Bali (Puspadewi \& Putra, 2014), gagasan bentuk 2D pada bangunan Masjid Jamik di kota Bengkulu (Lusiana, Afriani, Ardy, \& Widada, 2019), konsep simetri dan lingkaran pada alat musik Marawis (Marina \& Izzati, 2019), konsep nilai komparatif pada aktivitas petani kakao di Desa Temuasri Sempu Banyuwangi Jawa Timur (Aprilianti, Sunardi, \& Yudianto, 2019), dan konsep bentuk 2D pada kain Tapis dan Rumah Adat Lampung (Loviana, Merliza, Damayanti, Mahfud, \& Islamuddin, 2020).

Eksplorasi etnomatematika di Indonesia khususnya budaya sasak telah didokumentasikan oleh beberapa peneliti seperti, eksplorasi bangunan/rumah adat sasak (Supiyati, Hanum, \& Jailani, 2019), tradisi pengukuran masyarakat suku sasak dan penerapannya dalam pembelajaran matematika (Hardiani \& Putrawangsa, 2019). Berdasarkan hasil penelitian sebelumnya, belum ada penelitian yang mengeksplorasi lebih jauh terkait tenun sasak Sukarara. Oleh karena itu tujuan penelitian ini untuk mengeksplorasi unsur transformasi geometri tenun suku sasak Sukarara Lombok Tengah menurut sudut pandang etnomatematika. Temuan penelitian diharapkan dapat menjadi referensi bagi guru dan pemerhati pembelajaran matematika dalam rangka membuat buku teks dan pemanfaatan budaya lokal sebagai sumber belajar matematika di sekolah, sehingga siswa lebih tertarik, tertantang, dan termotivasi.

\section{Metode}

Penelitian ini merupakan jenis penelitian kualitatif dengan model etnografi (Creswell, 2010). Pemilihan model Etnografi karena sejalan dengan tujuan etnomatematika yaitu mengkaji ide, metode, dan teknik dalam budaya tertentu dari pandangan asli anggota budaya tersebut (Ascher \& D'Ambrosio, 1994; Shirley \& Palhares, 2016; Spradley, 2016). Prosedur penelitian dilakukan dengan pengaturan subjek penelitian yang dibiarkan mengalami tanpa perlakuan, namun peneliti bertindak sebagai observasi partisipan. Pengumpulan data dilakukan dengan studi lapangan dan wawancara dengan narasumber yang dipilih secara purposive yaitu Bapak Lalu Supardan seorang tokoh yang paham tentang budaya tenun Sukarara dan Ibu Baiq Kasmini seorang penenun asli Sukarara Lombok Tengah. Pemilihan 
narasumber atau informan mengacu pada kriteria yang ditetapkan oleh Umbara, Wahyudin, \& Prabawanto (2021) yaitu: 1) informan memiliki pemahaman yang baik tentang budaya dan kebiasaan masyarakat adat Sasak khususnya dalam menenun, 2) informan memiliki kemauan menjadi informan dan memiliki waktu yang cukup untuk memberikan informasi kapanpun dibutuhkan dan 3) informan dapat menyampaikan informasi secara lengkap baik dalam bahasa Sasak maupun bahasa Indonesia.

Pengumpulan data dalam penelitian ini dilakukan dengan studi lapangan dan wawancara langsung dengan dua informan yaitu Ibu Baiq Kasmini dan Bapak Lalu Supardan. Wawancara dengan Ibu Baiq Kasmini adalah untuk melihat, mendalami dan mengklarifikasi secara komprehensif bagaimana membuat motif tenun beserta dasar ilmu dan seni yang digunakan dalam pembuatan motif tenun. Peneliti juga melakukan wawancara dengan Pak Supardan, seorang tokoh adat yang paham tentang filosofi tenun sasak Sukarara dengan tujuan untuk menggali dan mengklarifikasi nilai-nilai budaya yang ada pada motif tenun Sukarara.

Pengumpulan data dilakukan langsung oleh seluruh peneliti dengan menggunakan alat perekam audio. Teknik pengumpulan data yang digunakan adalah mengadopsi desain penelitian etnografi dengan melakukan observasi partisipan dan wawancara mendalam. Peneliti melakukan observasi partisipan melalui partisipasi langsung dalam situasi atau setting yang mereka amati sedangkan wawancara mendalam adalah teknik utama yang digunakan oleh peneliti kualitatif untuk mengetahui ide, pendapat, dan pengalaman responden (Fraenkel et al., 2011). Pengamatan dilakukan terhadap penenun Sukarara yang sedang menenun.

Data penelitian dikumpulkan melalui observasi dan wawancara untuk menghasilkan catatan lapangan, rekaman audio, foto, dan rekaman video, kemudian dianalisis menggunakan teknik analisis isi dan triangulasi sumber data, serta terakhir dideskripsikan untuk mengeksplorasi setiap temuan dalam penelitian ini. Teknik analisis isi menyajikan data secara detail tentang budaya menenun dan kebiasaan subjek penelitian yang dilakukan di lokasi penelitian. Teknik triangulasi sumber data dilakukan dengan menggali secara komprehensif dengan melihat konsepsi matematis yang ada dalam motif tenun Sukarara dan dihubungkan dengan tinjauan pustaka tentang tenun Sukarara.

\section{Hasil Penelitian}

Berdasarkan hasil observasi dan wawancara, tenun yang dihasilkan oleh suku Sasak di Desa Sukarara Kabupaten Lombok Tengah Nusa Tenggara Barat menyimpan unsur-unsur matematika dan filosofis yang dapat dijadikan sumber belajar. Menenun dalam Bahasa Sasak 
dikenal dengan istilah "nyesek". Hal unik yang menjadi tradisi masyarakat Sukarara adalah kegiatan menenun merupakan sebuah keahlian yang wajib dimiliki oleh setiap perempuan di Desa Sukarara. Sebelum menikah, seorang perempuan di Sukarara wajib sudah bisa menenun, karena sebagai salah satu syarat untuk bisa menikah. Berikut transkrip wawancara dengan subjek.

Peneliti : Mohon diceritakan bagaimana budaya tenun ini bagi masyarakat di Desa Sukarera!

Subjek 1 : kata tenun dalam bahasa sasak adalah nyesek. Bagi masyarakat di Desa kami, menyesek ini wajib bagi perempuan-perempuan.

Peneliti : Wajaib bagaimana maksudnya!

Subjek 1 : Jadi Sebelum menikah, seorang perempuan di Desa kami wajib bisa menyesek, karena itu sebagai salah satu syarat untuk bisa menikah.

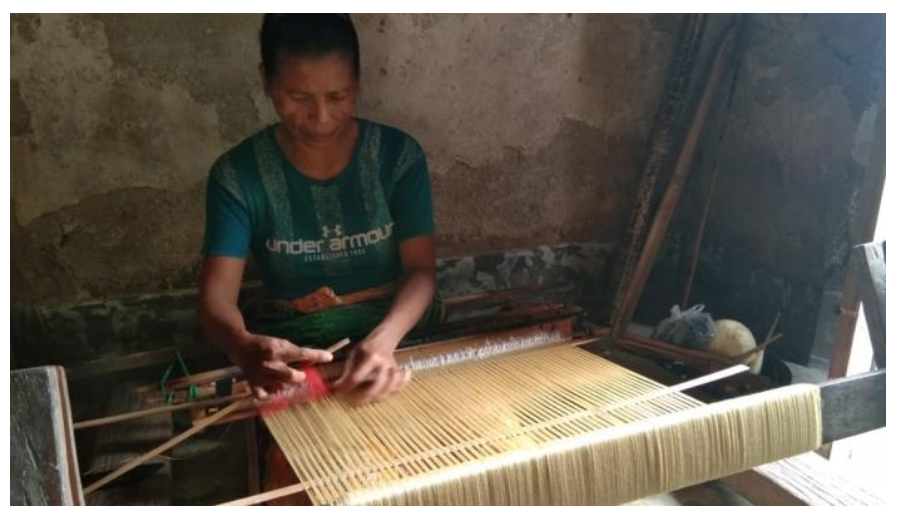

Gambar 1. Alat tenun traditional

Pembuatan kain tenun di Sukarara Lombok Tengah masih dilakukan dengan cara tradisional yaitu menggunakan alat tenun sederhana yang bukan mesin seperti yang disajikan pada Gambar 1. Tenun di Sukarara memiliki motif dan corak yang berbeda-beda dan setiap motif memiliki makna tersendiri. Motif-motif tenun khas Sukarara memiliki unsur keteraturan atau pola. Berdasarkan hasil pengamatan bahwa motif kain tenun Sukarara pada umumnya memadukan motif geometris seperti persegi panjang, persegi empat, garis memanjang, dan segitiga. Motif tersebut terbentuk dari hasil perpaduan benang pakan dan benang lungsin. Benang pakan merupakan benang dengan arah vertikal mengikuti panjang kain, sedangkan benang lungsin adalah benang dengan arah horizontal atau mengikuti lebar kain. Beberapa motif yang terkenal di Sukarara adalah motif wayang, subahnale, keker atau merak, bintang empat, dan alang atau lumbung. Berikut transkrip wawancara dengan subjek.

Peneliti : Ada berapa banyak jenis motif atau corak kain tenun di Desa Sukarara ini

Subjek 1: ada banyak pak, misalnya motif-motif yang terkenal, motif wayang, subahnale, keker atau merak, bintang empat, dan alang atau lumbung

Peneliti : Bagaimana proses mendapatkan motif-motif tersebut! 
Subjek 1: motif tersebut tergantung perpaduan benang pakan dan benang lungsin.

Peneliti : Apa itu benang pakan dan benang lungsin

Subjek 1: Benang pakan merupakan benang dengan arah vertikal mengikuti panjang kain, sedangkan benang lungsin adalah benang dengan arah horizontal atau mengikuti lebar kain

\section{Nilai Budaya dan Penerapan Transformasi Geometri pada Motif Tenun Wayang}

Berdasarkan hasil wawancara dengan Pak Supardan dan Ibu Kasmini diperoleh fakta bahwa motif wayang mengilustrasikan sepasang manusia yang memegang payung. Motif wayang ini terinspirasi dari sepasang pengantin yang memegang payung dalam acara nyongkolan (Kasmini, 2016; Supardan, 2021). Nyongkolan merupakan rangkaian prosesi pernikahan yang ada di Desa Sukarara. Pada acara nyongkolan, mempelai pria dan wanita akan diarak menuju rumah mempelai wanita. Prosesi nyongkolan ini bertujuan untuk memberikan pengumuman kepada masyarakat bahwa mempelai wanita dan pria telah resmi menjadi suami istri dan untuk menghindari fitnah di masyarakat jika suatu hari pasangan tersebut terlihat bersamaan.

Peneliti : Apa makna motif wayang

Subjek : motif wayang untuk menggambarkan pasangan yang memegang payung

Peneliti : pasangan bagaimana maksudnya

Subjek : Pasangan pengantin dalam acara nyongkolan, yang di arak menuju rumah mempelai wanita

Peneliti : apa tujuan nyongkolan

Subjek : Nyongkolan itu merupakan informasi bagi masyarakat bahwa mempelai wanita dan pria sudah resmi menjadi pasangan suami dan istri.

Selanjutnya, dikatakan bahwa motif wayang ini mengadopsi dari kisah wayang. Sepasang pengantin pada motif wayang dipercaya sebagai pasangan dari tokoh pewayangan yaitu Jayangrana dan Muni Garim. Jayangrana dan Muni Garim adalah sepasang raja dan ratu Mesir yang terdapat dalam kisah pewayangan masyarakat Lombok. Pada masa lampau wayang digunakan sebagai media penyebaran agama Islam di pulau Lombok. Pada pembuatan motif wayang ditemukan unsur transformasi geometri berupa pencerminan (refleksi) sebagaimana tampak pada Gambar 2 dan berikut hasil transkrip wawancara bersama subjek.

Peneliti : Apa makna motif wayang

Subjek : berdasarkan cerita-cerita bahwa motif wayang juga menggambarkan kisah wayang sepasang pengantin yang dipercaya adalah tokoh pewayangan Jayangrana dan Muni Garim

Peneliti : Siapa tokoh Jayangrana dan Muni Garin

Subjek : Jayangrana dan Muni Garim adalah sepasang raja dan ratu Mesir yang terdapat dalam kisah pewayangan masyarakat Lombok. 

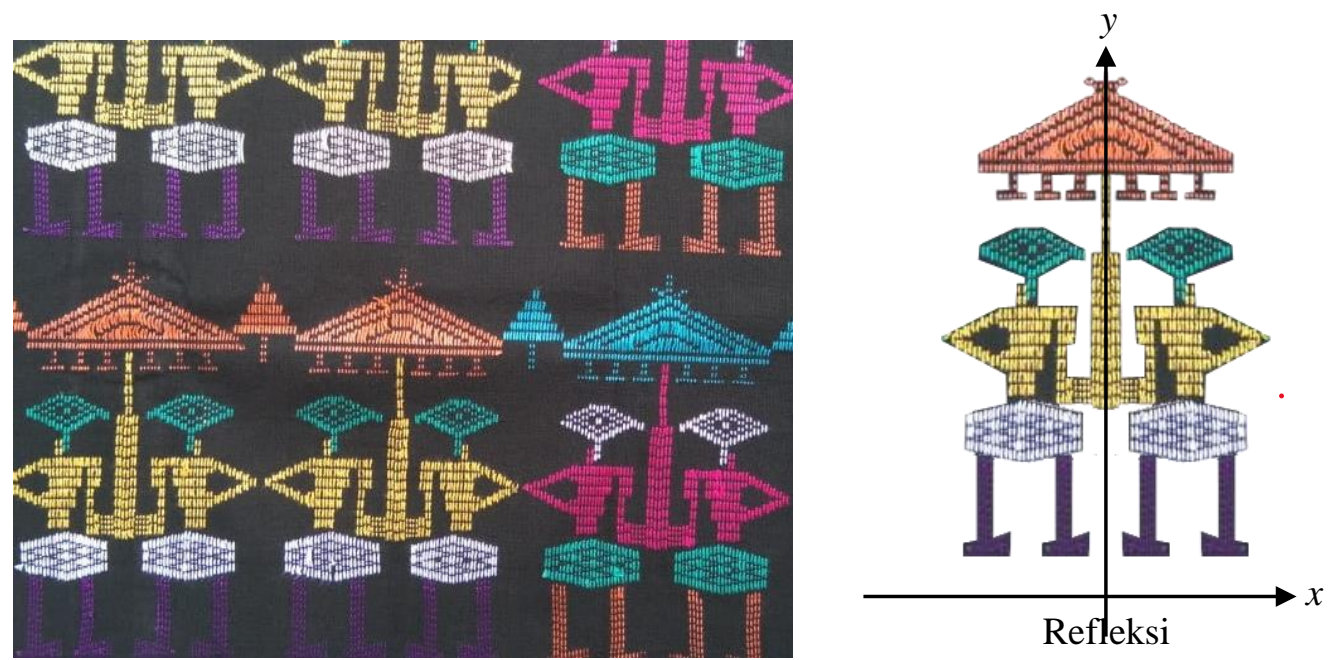

Gambar 2. Transformasi geometri pada motif wayang

\section{Nilai Budaya dan Penerapan Transformasi Geometri pada Motif Tenun Subahnale}

Filosofi kata Subahnale berawal dari seorang wanita yang membuat kain tenun yang memakan waktu cukup lama. Saat penenun selesai membuat, dibawalah kain tersebut keluar untuk ditunjukkan kepada semua orang, kemudian orang tersebut mengucapkan Subhanallah yang menunjukkan rasa takjub dan kagum melihat keindahan sebuah kain songket (Misnawati, 2016). Secara umum, motif Subahnale merupakan kombinasi dari bunga ceplok yang dikelilingi oleh motif geometri yang lebih dikenal dengan istilah kurungan. Kurungan yang dimaksud berupa motif bunga yang terletak di bagian tengah. Pada umumnya masyarakat Sukarara menggunakan warna dasar hitam dan merah marun. Pada pembuatan motif Subahnale ditemukan penerapan transformasi geometri berupa pencerminan (refleksi) dan translasi (pergeseran) sebagaimana tampak pada Gambar 3 dan berikut transkrip wawancara dengan subjek.

\section{Peneliti : Apa makna motif Subahnale}

Subjek : Ceritanya begini pak, kata orang-orang tua kami dulu. Motif Subahnale berasal dari wanita yang membuat kain tenun sangat lama, pada saat dia menunjukkan pada orang lain, orang tersebut kagum dan mengucapkan Subhanallah untuk menunjukkan rasa kagumnya saat melihat kain songket yang sangat indah

Peneliti : gambar apa saja ini (sambil menunjuk motif subahnale)

Subjek : Gambar bunga ceplok dan kurungan 


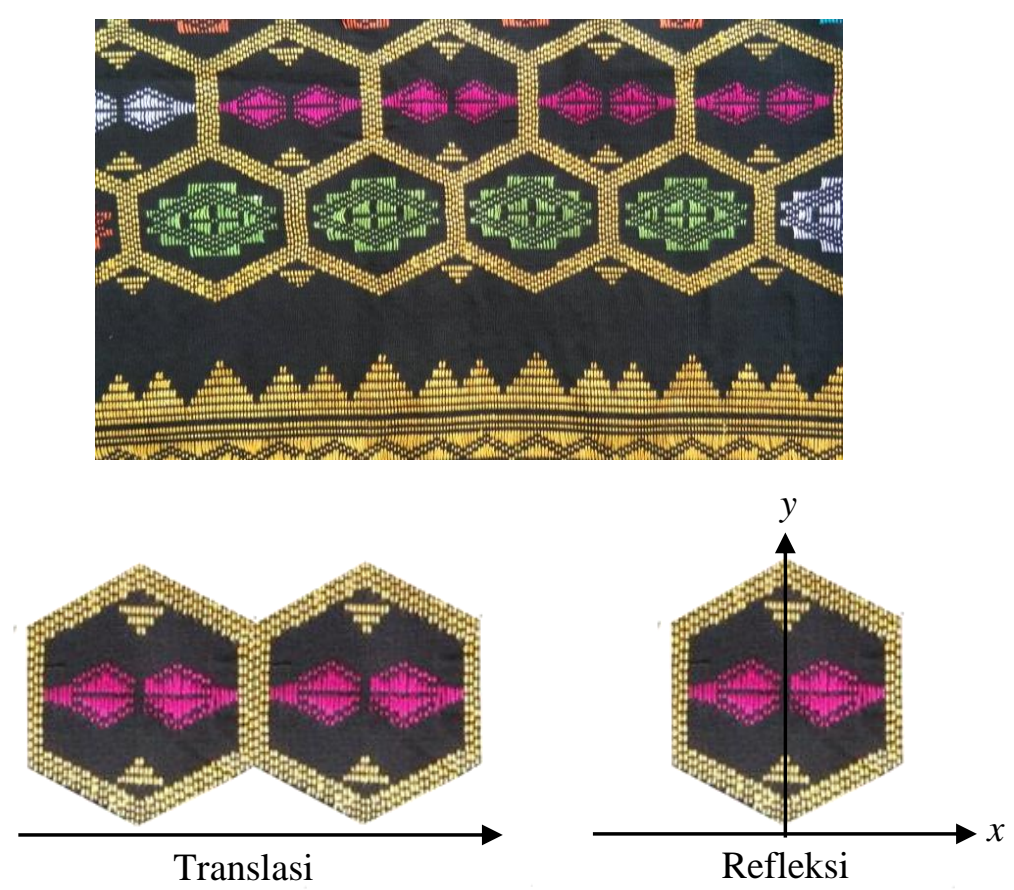

Gambar 3. Transformasi geometri pada motif subahnale

\section{Nilai Budaya dan Penerapan Transformasi Geometri pada Motif Tenun Keker}

Motif keker atau merak menggambarkan sepasang burung merak yang sedang bertengger di sebuah pohon. Motif keker menyimbolkan kedamaian dan kebahagiaan (Supardan, 2021). Secara umum motif keker menggunakan warna dasar gelap seperti biru tua atau hitam dan untuk motifnya menggunakan warna yang kontras dengan warna dasar seperti kuning cerah atau emas. Pada pembuatan motif keker digunakan ditemukan penerapan transformasi geometri berupa pencerminan (refleksi) sebagaimana tampak pada Gambar 4. Berikut transkrip wawancara dengan subjek.

\section{Peneliti : Apa makna motif keker}

Subjek : Motif keker itu adalah sepasang burung merak yang sedang bertengger di sebuah pohon yang menyimbolkan kedamaian dan kebahagiaan
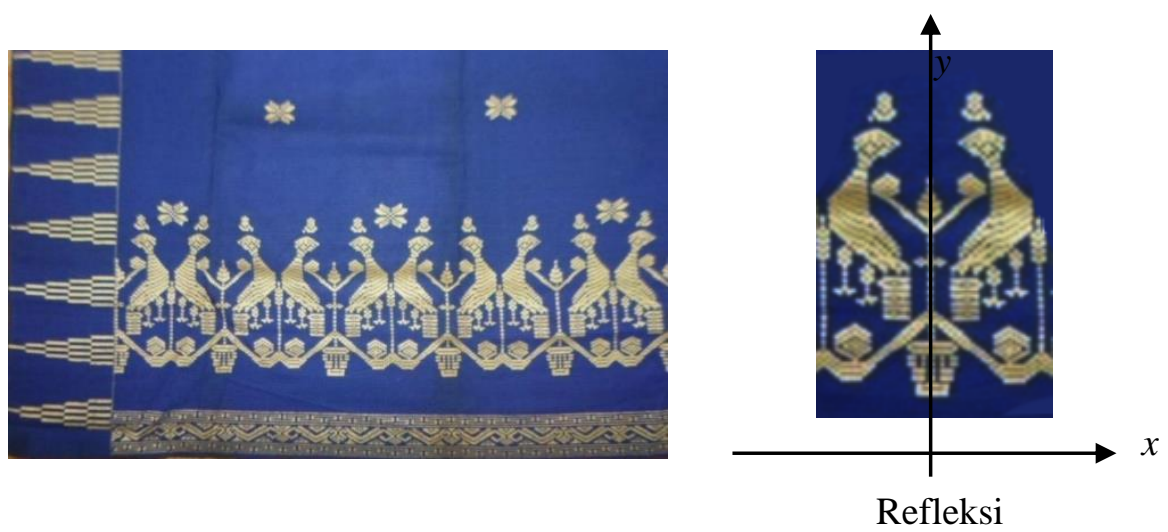

Gambar 4. Transformasi geometri pada motif keker 


\section{Nilai Budaya dan Penerapan Transformasi Geometri pada Motif Bintang Empat}

Motif bintang empat merupakan perpaduan antara motif bunga ceplok yang terletak di atas bidang kotak memanjang dan bagian tengahnya berbentuk bintang empat. Dinamakan bintang empat karena berhubungan dengan arah mata angin dan munculnya bintang timur sebagai pertanda bahwa fajar telah tiba (Misnawati, 2016; Supardan, 2021). Pada motif bintang empat, umumnya menggunakan warna dasar gelap seperti warna hitam dan untuk warna motif digunakan warna kontras. Sekitar tahun 2000-an penggunaan komposisi warna dasar dan warna motif telah banyak mengalami perubahan. Warna dasar kain songket yang biasanya berwarna hitam atau gelap dan sekarang mulai mengalami perubahan menggunakan warna cerah, seperti warna orange, putih atau kuning. Kain tenun motif bintang empat merupakan kain yang harus disiapkan bagi seorang perempuan yang akan menikah. Kain tenun motif bintang empat ini dibawa sebagai hadiah untuk calon suami. Pada pembuatan motif bintang empat ditemukan penerapan transformasi geometri berupa translasi sebagaimana tampak pada Gambar 5 dan transkrip wawancara dengan subjek.
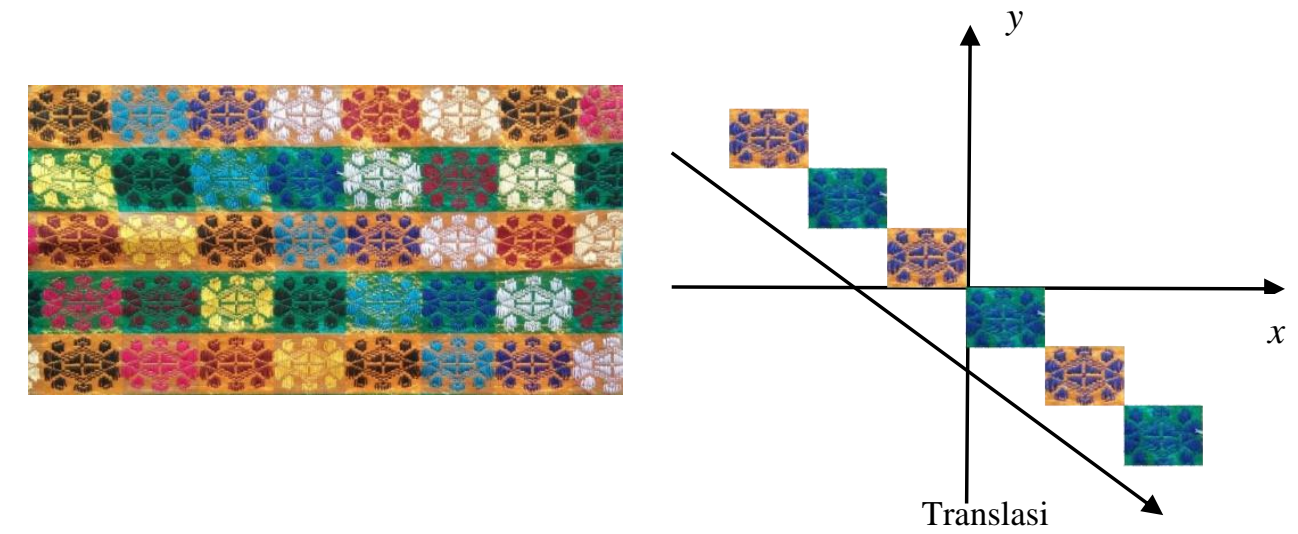

Gambar 5. Transformasi geometri pada motif bintang empat

Peneliti : Apa makna motif bintang empat

Subjek : Motif bintang empat merupakan perpaduan antara motif bunga ceplok yang terletak di atas bidang kotak memanjang dan bagian tengahnya berbentuk bintang empat.

Peneliti : Bintang empat bagaimana maksudnya

Subjek : Dinamakan bintang empat karena berhubungan dengan arah mata angin dan munculnya bintang timur sebagai pertanda bahwa fajar telah tiba.

\section{Nilai Budaya dan Penerapan Transformasi Geometri pada Motif Alang/Lumbung}

Motif alang juga dikenal dengan istilah motif lumbung. Lumbung merupakan tempat untuk menyimpan hasil bumi atau hasil panen dari masyarakat sasak. Motif alang atau lumbung menyimbolkan kesejahteraan dan kemakmuran karena musim panen telah tiba (Misnawati, 2016; Supardan, 2021). Jika dilihat lebih detail, motif alang digambarkan seperti 
gambar alang atau lumbung yang memiliki empat tiang atau penyangga. Warna dasar yang sering digunakan adalah warna hitam atau merah gelap. Pada pembuatan motif Alang/lumbung digunakan penerapan transformasi geometri berupa refleksi sebagaimana tampak pada Gambar 6 dan berikut transkrip wawancara dengan subjek.

Peneliti : Apa makna motif alang

Subjek : Motif alang juga disebut motif lumbung, lumbung itu, tempat menyimpan hasil panen masyarakat sasak dan motif lumbung sendiri menyimbolkan kesejahteraan dan kemamkmuran
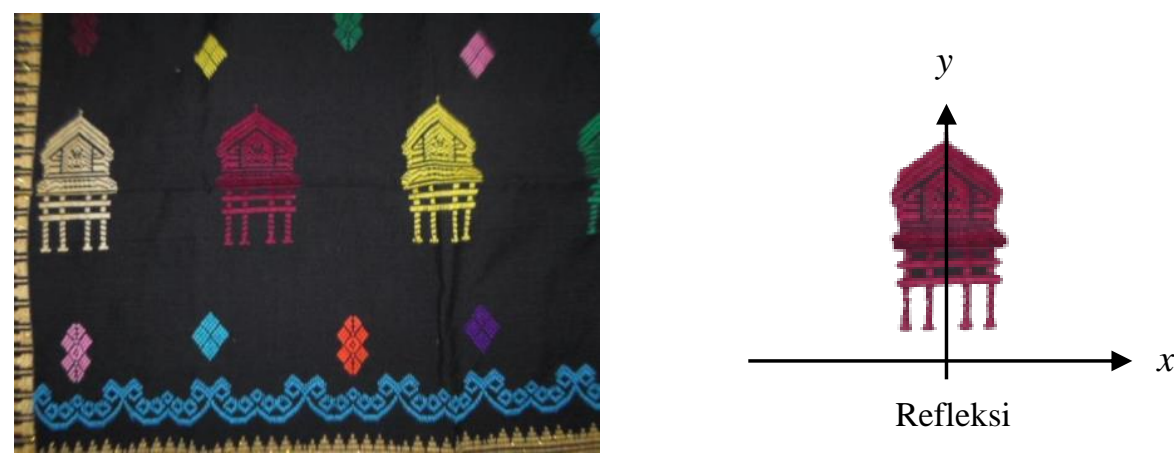

Gambar 6. Transformasi geometri pada motif alang/lumbung

\section{Pembahasan}

Eksplorasi transformasi geometri yang ditemukan dalam pembuatan motif tenun Sukarara menunjukkan bahwa dalam tenun suku Sasak menyimpan atau memuat konsep matematika. Hal tersebut sejalan dengan penelitian yang dilakukan oleh Prahmana \& D'Ambrosio (2020), secara umum konsep geometri transformasi yang ditemukan pada motif kain tenun adalah refleksi (pencerminan) dan translasi (pergeseran). Hasil penelitian juga menunjukkan bahwa pada setiap motif tenun Sukarara terkandung pesan moral yang mengandung ideologi, nilai, norma, etika yang mengatur bagaimana hubungan manusia dengan Tuhan, manusia dengan manusia, manusia dengan alam. Pada motif wayang menunjukkan sepasang pengantin yang memegang payung dalam acara nyongkolan, motif Subahnale menunjukkan rasa takjub dan kagum melihat keindahan sebuah kain songket, motif keker menyimbolkan kedamaian dan kebahagiaan, motif bintang empat berhubungan dengan arah mata angin dan munculnya bintang timur sebagai pertanda bahwa fajar telah tiba dan motif alang atau lumbung menyimbolkan kesejahteraan dan kemakmuran karena musim panen telah tiba. Unsur matematika sangat dekat dengan nilai moral dan budaya masayarakat (Supiyati, Hanum, \& Jailani, 2019; Prahmana \& D’Ambrosio, 2020; Umbara, Wahyudin, Prabawanto, 2021). 
Eksplorasi etnomatematika dalam budaya Indonesia dapat menjadi salah satu upaya agar pembelajaran matematika dekat dengan kehidupan sehari-hari dan budaya sehingga siswa dapat mengambil makna dari konsep matematika yang dipelajari untuk diterapkan dalam kehidupan sehari-hari (Abdullah, 2017; Risdiyanti \& Prahmana, 2018; 2020). Pembelajaran matematika berbasis etnomatematika juga dapat mengatasi miskonsepsi, ketidaktertarikan terhadap matematika, dan kecemasan (Prahmana \& Ambrosio, 2020). Temuan eksplorasi etnomatematika juga telah diterapkan dalam pembelajaran matematika dan pembelajaran matematika berbasis etnomatematika terbukti dapat mengubah pandangan siswa tentang hubungan antara matematika dengan budayanya (Prahmana \& D’Ambrosio, 2020).

\section{Simpulan}

Konsep transformasi geometri yang ditemukan pada motif tenun Sukarara Lombok Tengah adalah konsep refleksi (pencerminan) dan translasi (pergeseran) pada motif wayang, subahnale, keker, bintang empat, dan alang/lumbung. Kajian budaya pada tenun Sukarara melalui sudut pandang etnomatematika dapat mengeksplorasi konsep matematis seperti konsep transformasi geometri yang dapat digunakan dalam kegiatan belajar mengajar matematika di Lombok Nusa Tenggara Barat. Hal ini dapat diimplementasikan untuk meningkatkan pemahaman tentang transformasi geometri bagi siswa yang tinggal di pedesaan dan perkotaan. Saran untuk peneliti selanjutnya, lebih difokuskan pada rancangan perangkat pembelajaran berbasis etnomatematika agar pembelajaran matematika lebih menarik, menyenangkan, dan tidak terlalu abstrak karena konteksnya langsung terkait dengan budaya siswa.

\section{Referensi}

Abdullah, A. S. (2017). Ethnomathematics in perspective of Sundanese culture. Journal on Mathematics Education, 8(1), 1-16. https://doi.org/10.22342/jme.8.1.3877.1-15.

Aprilianti, I., Sunardi, S., \& Yudianto, E. (2019). Etnomatematika pada aktivitas petani kakao Desa Temuasri Sempu Banyuwangi sebagai bahan ajar siswa. Saintifika, 21(1), 1-8.

Ascher, M., \& D'Ambrosio, U. (1994). Ethnomathematics: a dialogue. For the Learning of Mathematics, 14(2), 36-43.

Creswell, J. W. (2012). Educational research fourth edition. Boston: Pearson education, Inc.

D'Ambrosio, U. (2016). An overview of the history of ethnomathematics. In Current and future perspectives of Ethnomathematics as a program (pp. 5-10). Cham: Springer. https://doi.org/10.1007/978-3-319-30120-4_2.

Fraenkel, J. R., Wallen, N. E., \& Hyun, H. H. (2011). How to design and evaluate research in education. New York: McGraw-Hill Humanities.

Hardiani, N., \& Putrawangsa, S. (2019). Etnomatematika tradisi pengukuran masyarakat suku Sasak dan potensi pengintegrasiannya dalam pembelajaran matematika. Aksioma: 
Jurnal Program Studi Pendidikan Matematika, 8(1), 159-174. https://doi.org/10.24127/ajpm.v8i1.1814.

Hastuti, Surahmat, Sutarto. (2019). Pembelajaran matematika sekolah dasar. Mataram: LPP Mandala

Loviana, S., Merliza, P., Damayanti, A., Mahfud, M. K., \& Islamuddin, A. M. R. (2020). Etnomatematika pada kain tapis dan rumah adat Lampung. Tapis: Jurnal Penelitian Ilmiah, 4(1), 94-110. https://doi.org/10.32332/tapis.v4i1.1956.

Lusiana, D., Afriani, N. H., Ardy, H., \& Widada, W. (2019). Eksplorasi etnomatematika pada masjid jamik kota Bengkulu. Jurnal Pendidikan Matematika Raflesia, 4(2), 164-176.

Mauluah, L., \& Marsigit. (2019). Ethnomathematics for elementary student: Exploration The Learning Resources at Kraton Yogyakarta. International Journal of Scientific and Technology Research, 8(7), 776-780.

Misnawati, Y. (2016). Makna simbolik kain songket Sukarara Lombok Tengah Nusa Tenggara Barat. Mataram: LPP Mandala

Prahmana, R. C. I., \& D’Ambrosio. (2020). Learning geometry and values from patterns: Ethnomathematics on the batik patterns of Yogyakarta, Indonesia. Journal on Mathematics Education, 11(3), 439-456. https://doi.org/10.22342/jme.11.3.12949.439$\underline{456}$.

Prahmana, R. C. I., Yunianto, W., Rosa, M., \& Orey, D. C. (2021). Ethnomathematics: pranatamangsa system and the birth-death ceremonial in Yogyakarta. Journal on Mathematics Education, 12(1), 93-112. https://doi.org/10.22342/jme.12.1.11745.93112 .

Puspadewi, K. R., \& Putra, I. G. N. N. (2014). Etnomatematika di balik kerajinan anyaman Bali. Jurnal Matematika, 4(2), 80-89.

Risdiyanti, I., \& Prahmana, R. C. I. (2017). Ethnomathematics: Exploration in Javanese culture. Journal of Physics: Conference Series, 943(1), 012032. https://doi.org/10.1088/1742-6596/943/1/012032.

Risdiyanti, I., Prahmana, R. C. I., \& Shahrill, M. (2019). The learning trajectory of social arithmetic using an Indonesian traditional game. Elementary Education Online, 18(4), 2094-2108. https://doi.org/10.17051/ilkonline.2019.639439.

Rosa, M., \& Orey, D. C. (2016). State of theart in ethnomathematics. In M. Rosa, U. D’Ambrosio, D.C. Orey, L. Shirley, W. V. Alangui, P. Palhares, \& M. E. Gavarrete (Eds.). Current and future perspectives of ethnomathematics as a program (pp. 11-37). Cham: Springer. https://doi.org/10.1007/978-3-319-30120-4_3.

Shirley, L., \& Palhares, P. (2016). Ethnomathematics and its diverse pedagogical approaches. In Current and future perspectives of Ethnomathematics as a program (pp. 25-44). Cham: Springer. https://doi.org/10.1007/978-3-319-59220-6.

Spradley, J. P. (2016). The ethnographic interview. California: Waveland Press.

Supardan, L. (2021). Filosofi dan makna tenun khas Sukarara. Komunikasi Personal

Supiyati, S., Hanum, F., \& Jailani. (2019). Ethnomathematics in Sasaknese architecture. Journal on Mathematics Education, 10(1), 47-57. https://doi.org/10.22342/jme.10.1.5383.47-58.

Umbara, U., Wahyudin, W., \& Prabawanto, S. (2021). Exploring ethnomathematics with ethnomodeling methodological approach: How does cigugur indigenous people using calculations to determine good day to build houses. Eurasia Journal of Mathematics, Science and Technology Education, 17(2), em1939. https://doi.org/10.29333/ejmste/9673.

Widodo, H. (2019). The role of school culture in holistic education development in Muhammadiyah elementary school Sleman Yogyakarta. Dinamika Ilmu, 19(2), 265285. https://doi.org/10.21093/di.v19i2.1742. 